\title{
Reversible Posterior Leukoencephalopathy Syndrome
}

\author{
Andrew D. Norden Tracy T. Batchelor \\ Division of Neuro-Oncology, Department of Neurology, Massachusetts General Hospital and Harvard Medical School, Boston, MA, USA
}

The reversible posterior leukoencephalopathy syndrome (RPLS) was first identified 10 years ago by Hinchey et al. [1]. This disorder is characterized by the subacute onset of headache, impaired mentation, seizures, and a variable degree of visual loss. In typical cases, cranial magnetic resonance imaging (MRI) demonstrates symmetric T2 hyperintensities involving the bilateral parietal and occipital white matter $[2,3]$ (fig. 1). In the only published case report of a brain biopsy in an RPLS patient, pathological analysis revealed white matter edema without other recognizable abnormalities [4]. A number of better characterized conditions including hypertensive encephalopathy, eclampsia, and cyclosporine neurotoxicity are thought to represent RPLS subtypes. The list of conditions and drugs associated with RPLS is expanding and includes a number of factors relevant to the oncologist: high-dose corticosteroids, chemotherapeutic agents (cytarabine, cisplatin, L-asparaginase, and some multidrug regimens), immunosuppressants (cyclosporine and tacrolimus), bone marrow transplantation, interferon alfa, blood product transfusion, erythropoietin, and granulocyte colony stimulating factor (G-CSF). RPLS has been reported in cancer patients treated with bevacizumab, a monoclonal antibody that inhibits vascular endothelial growth factor, perhaps because of its tendency to produce hypertension [5-7]. A case of RPLS was also reported in a patient treated with sorafenib, a RAF kinase inhibitor with anti-angiogenic properties [8].

Clinicians have observed that RPLS is neither always reversible [9] nor always localized exclusively to brain tissue supplied by the posterior circulation [10]. In many cases, gray matter is involved in addition to white matter. For these reasons, RPLS is considered by many to be a misnomer [11]. These observations challenge the prevailing theory of RPLS pathogenesis which is based on studies of hypertensive encephalopathy and eclampsia. RPLS is thought to develop when elevated blood pressure exceeds the ability of the cere- bral vasculature to autoregulate [1]. The result is fluid transudation into the extracellular space and vasogenic edema. This process may preferentially impact the posterior circulation because of a relative lack of sympathetic innervation. Cyclosporine and tacrolimus may lead to RPLS by a toxic effect on endothelial cells that increases vascular permeability, though experimental evidence is limited. Others have proposed that RPLS results when elevated blood pressure or an endothelial cell toxin provokes severe vasoconstriction followed by infarction and cytotoxic edema [12].

Because some cases of RPLS progress to hemorrhage or infarction with permanent neurological sequelae, prompt recognition of the syndrome and institution of therapy are critical. No specific treatment has proven superior, but the majority of patients recover completely following withdrawal of the causative agent, strict blood pressure control, and administration of antiepileptic drugs. It is recommended that the patient not be re-exposed to the causative agent, though no data are available to guide decision-making in such circumstances. Urgent neurological consultation is advisable in all cases.

In this issue of ONKOLOGIE, Haefner et al. [13] report the case of a 62-year-old woman with non-Hodgkin's lymphoma of the colon who developed RPLS 10 days after the second cycle of rituximab, cyclophosphamide, doxorubicin, vincristine, and prednisone (R-CHOP) with G-CSF rescue. Her case is typical of RPLS as she presented with lethargy that evolved over a matter of hours into stupor, followed by multiple generalized seizures. Partial seizures with secondary generalization are often observed in patients with RPLS. In the current case, blood pressure at the time of presentation was elevated $(165 / 70 \mathrm{~mm} \mathrm{Hg})$, as is true of most cases. Cranial MRI revealed bilateral cortical and subcortical T2 hyperintensities that primarily involved the posterior portions of the brain in a symmetric fashion. After aggressive management of hyperten-

\begin{tabular}{ll}
\hline KARGER & @ 2007 S. Karger GmbH, Freiburg \\
Fax +497614520714 & Accessible online at: \\
$\begin{array}{l}\text { E-mail Information@Karger.de } \\
\text { www.karger.com }\end{array}$ & www.karger.com/onk \\
&
\end{tabular}

Tracy T. Batchelor, M.D., M.P.H.

Massachusetts General Hospital, Department of Neurology, Division of Neuro-Oncology Stephen E. and Catherine Pappas Center for Neuro-Oncology

55 Fruit Street - Yawkey 9E, Boston, MA 02114 USA

Tel. +1 617 643-1938, Fax -2591

E-mail tbatchelor@partners.org 
Fig. 1. Cranial MRI in reversible posterior leukoencephalopathy syndrome. This axial fluid-attenuated inversion recovery (FLAIR) MRI was obtained in a 64-year-old woman with hypertensive encephalopathy. Typical features of RPLS seen here include bilateral, symmetric, FLAIR hyperintensities involving the posterior cerebral white matter. Subtle involvement of cerebral cortex and brainstem is also apparent.

sion and seizure control, the patient improved rapidly and was left without neurological sequelae.

Though RPLS often presents with distinctive clinical features and neuroimaging findings, some cases may be diagnostically challenging. Other potentially life-threatening illnesses such as stroke and meningoencephalitis should be considered in the differential diagnosis. In RPLS, the calcarine and paramedian occipital lobe structures are characteristically spared on imaging studies [1], whereas these regions are involved in bilateral posterior cerebral artery strokes due to 'top of the basilar' syndrome [14]. Diffusion-weighted imaging and apparent diffusion coefficient maps are very useful in distinguishing ischemic stroke from vasogenic edema [9]. When central nervous system infection cannot be ruled out on the basis of clinical features, lumbar puncture for microbiological studies should be performed, as in the current case. Neuroimaging must be obtained prior to a lumbar puncture in patients with altered mental status or unexplained seizures because of the risk of herniation in patients with intracranial mass lesions [15].

As in most cases of RPLS, the causative agent in the current case cannot be determined with certainty. Established risk factors for RPLS in this patient include hypertension, CHOP chemotherapy [16], and G-CSF rescue [17]. The relative contribution of each of these factors is unclear. Of course, the large majority of patients treated with $\mathrm{CHOP}$ and G-CSF do not develop RPLS. The specific host factors that predispose a patient to RPLS are unknown. The few patients who have been reported to have recurrent bouts of RPLS represent an opportunity for investigations that may shed light on the pathophysiology of this poorly understood disease [18].

\section{References}

1 Hinchey J, Chaves C, Appignani B, Breen J, Pao L, Wang A, Pessin MS, Lamy C, Mas JL, Caplan LR: A reversible posterior leukoencephalopathy syndrome. N Engl J Med 1996;334:494-500.

$\checkmark 2$ Kinoshita T, Moritani T, Shrier DA, Hiwatashi A, Wang HZ, Numaguchi Y, Westesson PL: Diffusionweighted MR imaging of posterior reversible leukoencephalopathy syndrome: a pictorial essay. Clin Imaging 2003;27:307-15.

>3 Mukherjee P, McKinstry RC: Reversible posterior leukoencephalopathy syndrome: evaluation with diffusion-tensor MR imaging. Radiology 2001;219: 756-65.

4 Schiff D, Lopes MB: Neuropathological correlates of reversible posterior leukoencephalopathy. Neurocrit Care 2005;2:303-5.

$\checkmark 5$ Allen JA, Adlakha A, Bergethon PR: Reversible posterior leukoencephalopathy syndrome after bevacizumab/FOLFIRI regimen for metastatic colon cancer. Arch Neurol 2006;63:1475-8.

6 Ozcan C, Wong SJ, Hari P: Reversible posterior leukoencephalopathy syndrome and bevacizumab. N Engl J Med 2006;354:980-2; discussion 980-2.
7 Glusker P, Recht L, Lane B: Reversible posterior leukoencephalopathy syndrome and bevacizumab. N Engl J Med 2006:354:980-2; discussion 980-2.

8 Govindarajan R, Adusumilli J, Baxter DL, ElKhoueiry A, Harik SI: Reversible posterior leukoencephalopathy syndrome induced by RAF kinase inhibitor BAY 43-9006. J Clin Oncol 2006; 24:e48.

9 Ay H, Buonanno FS, Schaefer PW, Le DA, Wang B, Gonzalez RG, Koroshetz WJ: Posterior leukoencephalopathy without severe hypertension: utility of diffusion-weighted MRI. Neurology 1998;51: 1369-76.

10 Ahn KJ, You WJ, Jeong SL, Lee JW, Kim BS, Lee JH, Yang DW, Son YM, Hahn ST: Atypical manifestations of reversible posterior leukoencephalopathy syndrome: findings on diffusion imaging and ADC mapping. Neuroradiology 2004;46:978-83.

11 Stott VL, Hurrell MA, Anderson TJ: Reversible posterior leukoencephalopathy syndrome: a misnomer reviewed. Intern Med J 2005;35:83-90.

12 Henderson RD, Rajah T, Nicol AJ, Read SJ: Posterior leukoencephalopathy following intrathecal chemotherapy with MRA-documented vasospasm. Neurology 2003;60:326-8.
13 Haefner MD, Siciliano RD, Widmer LA, Vogel Wigger BM, Frick S: Reversible Posterior Leukoencephalopathy Syndrome after Treatment of Diffuse Large B-Cell Lymphoma. Onkologie 2007;30:138-140.

14 Caplan LR: 'Top of the basilar' syndrome. Neurology 1980;30:72-9.

15 Roos KL: Lumbar puncture. Semin Neurol 2003;23: 105-14.

16 Edwards MJ, Walker R, Vinnicombe S, Barlow C, MacCallum P, Foran JM: Reversible posterior leukoencephalopathy syndrome following $\mathrm{CHOP}$ chemotherapy for diffuse large B-cell lymphoma. Ann Oncol 2001;12:1327-9.

17 Kastrup O, Diener HC: Granulocyte-stimulating factor filgrastim and molgramostim induced recurring encephalopathy and focal status epilepticus. J Neurol 1997;244:274-5.

18 Thaipisuttikul I, Phanthumchinda K: Recurrent reversible posterior leukoencephalopathy in a patient with systemic lupus erythematosus. J Neurol 2005; 252:230-1. 